\title{
Oil Price and Exchange Rate Nexus in Nigeria: Are there Asymmetries
}

\begin{abstract}
Attahir B. Abubakar ${ }^{1}$
This paper examines the dynamics in the relationship between oil price and exchange rate in Nigeria by utilizing monthly data spanning January 1986 to June 2018. It specifically determines asymmetries in the relationship between oil price and exchange rate and the effect of oil price shocks on exchange rate. Threshold Autoregressive (TAR), Momentum Threshold Autoregressive (MTAR) and Structural Vector Autoregressive (SVAR) models were employed for the analysis. Findings of TAR and MTAR models confirm the absence of asymmetric cointegration, hence leading to the conclusion that in the case of Nigeria, there are no asymmetries in the relationship between oil price and exchange rate. Findings from the SVAR model show gradual appreciation (though with some time lag) of naira following positive shocks to oil price. The study recommends among others the need for diversification of foreign exchange earnings base of the economy, so as to minimise the effect of negative shocks to oil price.
\end{abstract}

Keywords: Asymmetric, Exchange Rate, MTAR, Nigeria, Oil Price, SVAR, TAR

JEL Classification: F31, Q41.

DOI: $10.33429 /$ Cjas.10119.1/6

\subsection{Introduction}

The Nigerian economy is largely oil-based, with crude oil being the mainstay of the economy. Although oil's contribution to GDP is relatively small; 8.09 per cent and 10.04 per cent in Q3 2016 and Q3 2017, respectively (NBS, 2017), it accounts for the largest share of government revenue. Babatunde (2015) noted that oil accounts for about 90 per cent of total foreign exchange revenue to the economy. In addition, though oil revenue as a share of total government revenue declined from about 75 per cent in 2012 to about 47 per cent in 2016 (CBN, 2017), it still plays a major role in shaping the bearing of the Nigerian economy. The massive

\footnotetext{
${ }^{1}$ Department of Economics, Business School, Ahmadu Bello University, Zaria - Nigeria. attahirbabaji@gmail.com
} 
decline in crude oil price from an annual average of 111 dollars per barrel in 2012 to about 53 dollars per barrel in 2016 (EIA, 2018) can be alluded to as the major reason for a decline in share of oil revenue in total government revenue and not structural changes in the economy. Considering the over reliance of the economy on oil vis-a-vis volatility of the oil market; the Nigerian economy is exposed to external shocks from the oil market (Abubakar, 2017). This is apparent in the sharp decline in oil prices that led to the economy sliding into recession from Q1 2016 through to Q2 2017.

With oil accounting for the largest share of foreign exchange earning to the Nigerian economy, its role in determining the value of the foreign exchange rate of the Nigerian Naira cannot be over emphasized. The pass through of changes in oil price to exchange rate particularly for oil exporting and importing economies is entrenched in both theory and practice. This is more pronounced when considering the fact that oil is an important source of energy for countries as well as the major export product of some economies. The debate as to the effect as well as nature of pass through of oil prices (priced in US Dollar) to exchange rate of nations have continued to receive attention from economists and policy makers particularly, with recent developments in the international oil market occasioned by the rise and fall in oil prices.

From the theoretical standpoint, the effect of oil price shocks on oil exporting economies is expected to differ from that of oil importing economies. Abed, et al. (2016) noted that an increase in oil price transfers wealth from oil importing nations to oil exporting nations. A positive shock in the price of oil is expected to lead to an appreciation of the exchange rate of an oil exporting nation through an increase in foreign exchange earnings and a buildup of foreign exchange reserve. The exchange rate of oil importing nations, is however, expected to depreciate (Buetzer, et al. 2012). Nigeria's situation is somewhat paradoxical; it is a major exporter of crude oil and at the same time, a major importer of refined petroleum products. This makes the Nigerian case a unique one because the pressure on exchange rate following oil price change comes from both the nation's status of being an exporter of crude oil and importer of petroleum related products. Examining 
the asymmetries in the relationship between oil price and exchange for a country like Nigeria with this mixed status will deepen our understanding of the dynamics that abound.

With regards to pass through of changes in oil price to exchange rate, several studies have been conducted applying varying methods and techniques. The approaches followed by most of the studies can be summarized into two angles. The first group assumes the pass through of change in oil price to exchange rate to be symmetric, hence linear econometric models were employed. Studies by Pershin, et al. (2016); Brahmasrene, et al. (2014); Volkov and Yuhn (2016); Hussain, et al. (2017) among others fall under this category. On the other hand, studies by Buetzer et al. (2012); Abed et al (2016); Ahmad and Hernandez (2013); Tiwari and Albulescu (2016); Atems, et al. (2015) among others assumes the pass through to be asymmetric and therefore employed non-linear models for analysis. Furthermore, most of the studies that employed the non-linear methodologies supported the presence of asymmetries in the pass through. However, even with the application of non-linear methodologies, symmetric rather than asymmetric pass through was confirmed (Wang \& Wu, 2012 and Babatunde, 2015) indicating that the pass-through of oil price to exchange rate can take both symmetric and asymmetric fashion. From the studies reviewed above, it can be deduced that the relationship between oil price and exchange rate is still an area of research yet to be finalized.

The main objective of this study is to examine if there are asymmetries in the nexus between oil price and exchange rate of the Nigerian Naira. Further, the study investigated the impact of oil price shocks on exchange rate of the Naira. This is more interesting considering the fact that the Nigerian situation is unique, twinning as both an oil exporting and petroleum product importing nation. To achieve this objective, the study employs both asymmetric and symmetric methodologies, this in contrast to Muhammad, et al. (2011); Adeniyi, et al. (2012); Ogundipe and Ogundipe (2013); Ogundipe, et al. (2014) and Osuji (2015) who employed linear econometric models. Although Babatunde (2015) and Mordi and Adebiyi (2010) attempted to examine the influence of oil price increase and decrease on exchange 
rate in Nigeria, the study assumed the presence of asymmetric relationship without employing any formal asymmetry testing technique. This study build on the literature by first employing the TAR model to examine the presence or otherwise of asymmetries in the relationship between the variables and subsequently examining the impact of oil price shock on exchange rate dynamics.

The study provides monetary authorities with a better understanding of the dynamics between oil price and exchange rate, which goes a long way in aiding better policy decision, particularly for the Nigeria economy where oil plays a major role in influencing the dynamics of the economy. The rest of the paper is structured as follows Section 2 reviews the theoretical and empirical literature on the subject matter, while Section 3 covers the econometric techniques adopted, as well as data description. Section 4 presents and discusses findings of the study, while Section 5 concludes the paper.

\subsection{Literature Review}

\subsection{Theoretical Literature}

The relationship between exchange rate and oil price is entrenched in theory. The pass through of changes in oil price to exchange rate can be understood from the point of view of three channels: Balance of payment; Terms of Trade; and Elasticity (Beutzer et al. 2012; Abed et al. 2016). Krugman (1983) originated the idea of the balance of payment transmission channel of oil price to exchange rate. This channel is also known as the "wealth transmission channel" (Abed et al., 2016). Krugman (1983) and Golub (1983) found that with higher oil prices, wealth will be transferred from the oil importing nations to oil exporting nations. For an oil importing nation, a positive shock to oil price leads to a depreciation of its currency relative to the exporting nation. However, the level of depreciation depends on the degree of dependence on oil. On the other hand, for an oil exporting economy, its currency appreciates relative to the importing nation even though the level of appreciation depends on its importation of non-oil commodities (Fratzscher, et al. 2014; Buetzer et al., 2012). 
Under the terms of trade channel of oil price pass-through to exchange rate, the economy is classified into two sectors; the tradable and non-tradable sectors (Abed et al. 2016; Amano and Van Norden, 1988). The assumption here is that both the non-tradable and tradable sectors utilize a tradable input which is oil as well as a non-tradable input which is labour, further, since the price of outputs in the tradable sector is fixed internationally, it is the case that real exchange rate of a country is influenced by the prices of output from the non-tradable sector. Benessy-Quere, et al. (2007) posit that the response of real exchange rate to oil price shocks depends on the intensity of oil usage as an input in both the tradable and non-tradable sectors. In the event the non-tradable sector utilizes less energy (oil) than the tradable sector and a positive oil shock occurs, the price of its output falls leading to depreciation of the currency, but in a situation where the non-tradable sector utilizes more oil than the tradable sector, an increase in oil price leads to an increase in the non-tradable sector's output prices hence an appreciation of the currency. This occurs following the argument of Benessy-Quere et al. (2007) that real exchange rate is influenced by the prices of outputs of the non-tradable sector.

Proponents of the elasticity channel argue that the transmission of changes in oil price to exchange rate depends on the elasticity of oil import demand of a nation (Nkomo, 2006; Abed et al., 2016). If the import demand of oil of a nation is elastic and oil price increases, it can cut down its oil demand which has the tendency of appreciating its currency or at least neutralizing the effect of increase in oil price. On the other hand, if the import demand is inelastic, oil price increase leads to depreciation of the currency of the oil importing economy.

It could be understood from the theoretical standpoint that positive oil price shock is expected to have an appreciating effect on the currency of oil exporting economies while the effect on exchange rate of importing economies depends on their adjustment mechanisms. 


\subsection{Empirical Literature}

Extant empirical literature on the relationship between oil price and exchange rate has produced mixed results. Some of the studies that examined this relationship includes Lizardo and Mollick (2010) analyzed a panel of oil importing and exporting economies and found increase in oil price to have an appreciation effect on the exchange rate of oil exporting economies while depreciating that of oil importing economies. Similarly, Syed et al. (2012) employed the SVECM model and found that positive oil price shocks have a depreciating effect on the US Dollar exchange rate in the short run. Reboredo (2012) found that although there is an increase of dependence between oil price and exchange rate after the global financial crises; the level can still be termed as non-extreme market dependence. Further, Buetzer et al. (2012) analyzed a panel of 44 developed and emerging economies and found no evidence of exchange rate of oil exporting counties appreciating against those of oil importing countries following positive oil price shocks. Wang and Wu (2012) examined the linear and non-linear relationship between exchange rate and energy prices. Findings of the study showed that in the pre-2008 crises period, a uni-directional causality running from petroleum prices to exchange rate was found but in the post crises period a non-linear bi-directional causality between the variables was found.

In the same vein, Tiwari et al. (2013) also employed the Wavelet analysis to investigate the influence of oil prices on real exchange rate of Romania. Result shows oil price as having strong influence on exchange rate in both short and long run. Similarly, Beckmann and Czudaj (2013) employed the Markov-Switching VECM approach and found that time varying causality patterns runs from the nominal exchange rate angle to the nominal oil prices. Ahmad and Hernanadez (2013) investigated the long run asymmetric adjustment of oil price and exchange rate of 12 major producing and consuming nations employing the TAR and MTAR models. Findings of the study showed presence of asymmetries in Brazil, UK and Nigeria with higher adjustment after positive shock than negative oil price shock.

Further, Brahmasrene et al. (2014) found exchange rate to Granger cause oil prices in the short run, but in the medium and long run oil price shocks was found to 
significantly impact exchange rate fluctuations. Uddin et al. (2014) employed the Wavelet analysis to examine the relationship between exchange rate of Japan and oil prices. Findings of the study show that the magnitude of relationship between the variables kept changing over time horizon hence underscoring the significant effect of oil prices on exchange rate. Also, Fratzscher et al. (2014) examined the relationship between oil price, exchange rate and asset prices. Findings of the study shows a bi-directional causality between exchange rate and oil prices with increase in oil price having a depreciating effect on exchange rate. Similarly, Fowowe (2014) examined the nexus between exchange rate and oil price for South Africa and found increase in oil price as leading to depreciation of the South African exchange rate against the US dollar. Turham et al. (2014) employed the DCC model to study the G20 nations and found a strengthening negative relationship between oil prices and exchange rates.

In addition, Babatunde (2015) investigated the impact of oil price shocks on exchange rate in Nigeria. Result of the study shows positive price shocks to have a depreciating effect on exchange rate while negative price shock was found to appreciate exchange rate. Brayek et al. (2015) employed the DCC-MGARCH model to examine the relationship between oil price and exchange rate. Findings of the study show oil price and exchange rate to be independent in the pre-crises period, but however in the post-crises period a positive dependence was found pointing to the influence of oil price on exchange rate. Further, Atems et al. (2015) found oil supply shocks as having no bearing on exchange rate, but aggregate global oil demand shock was found to have a depreciating effect on exchange rate. Evidence of asymmetric response of exchange rate was also found.

Similarly, Tiwari and Albulescu (2016) employed the Wavelet approach and Asymmetric multi-horizon Granger-Causality test to examine the relationship between oil price and exchange rate of India. Results of the study showed exchange rate to granger cause oil price in the long run while the opposite result was found in the short run. Also, evidence of a non-linear and asymmetric relationship was found between the variables. Volkov and Yuhn (2016) found that exchange rate volatility in Russia, Brazil and Mexico to be associated with oil price shocks. However weak 
relationship was found in Canada and Norway. Asymmetric response of exchange rate was found to be associated with financial markets rather than oil revenues. Also, Pershin et al. (2016) studies the dynamics of oil price and exchange rate in some selected African countries and concluded that generalizations in the behavior of the relationship would not be made across all countries. Currencies of some oil-importing nations was found to appreciate during peak of oil price period.

Further, Abed et al. (2016) applied the GJR-GARCH model to study some selected MENA countries. Findings showed the presence of asymmetric adjustment with oil price increase, leading to appreciation of currencies of oil exporting economies, while a fall in oil price led to appreciation of currencies of oil importing nations. Chen et al. (2016) investigated the impact of oil price shocks on exchange rate of 16 OECD countries. They found that response of exchange rate to oil price differed when oil price change is driven by aggregate demand from aggregate supply. Evidence of non-linear relationship between the variables was not found. Also, Hussain et al. (2017) applied the detrended cross-correlation coefficient to analyze the relationship between oil prices and exchange rate of 12 Asian economies. Presence of co-movements as well as weak negative cross-relation between the variables was found.

From the review of theoretical literature, it can be deduced that the effect of oil price change (increase or decrease) depends on the status of a nation. The effect of a positive oil price shock on exchange rate of an oil-exporting nation is expected to be an appreciating currency; however, for an oil-importing nation, the effect is premised upon their adjustment capabilities. The review of empirical literature identified lack of consensus in the relationship between the variables. Some studies found symmetric effects of oil price change on exchange rate while others established asymmetric effect.

\subsection{Stylized Fact in Oil Price and Exchange Rate}

In this section, we make a graphical analysis of the dynamics of the study variables over the study period. Doing the above gives us an idea about the data behavior 
over time. Figure1 presents the graphical illustration of the movement of both oil price and exchange rate from January 1986 through June 2018. From the graph, oil price (red line) maintained a mild fluctuation from 1986 up to the year 1998 where it dipped a bit and thereafter maintained a graduating positive trend reaching its peak in the year 2007-2008 (at a price of about $\$ 138$ for a barrel of crude oil). Following the global financial crises of year 2008, oil price witnessed a sharp fall but this did not last long as the price began to rise in the year 2009 reaching a high price ridge around the year 2010 where oil price hovered over $\$ 100$ for a barrel up to the year 2014. From the year 2014, oil price began to fall again dipping down to about 30 dollar a barrel, after which it gradually began to rise. The above depicts the fact that relative stability was witnessed in the crude oil market from the year 1986 to around year 2003, after which periods of high rise and sharp drops were noticed. This is an indication that in the past decade, the crude oil market became more unstable and Nigeria's over dependence on crude oil greatly exposes the economy to the shocks of the oil market.

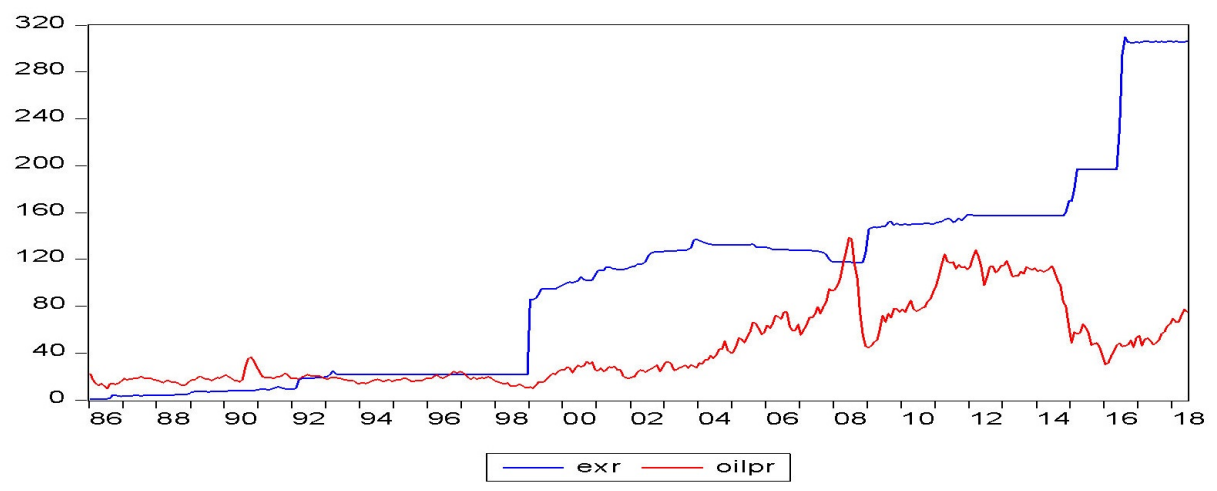

Figure 1: Trend of Oil Price and Exchange Rate

The behavior of exchange rate of the naira exhibited stability at different levels of exchange ridge. The exchange rate stabilizes and afterwards, a jump is witnessed pushing it up to another level where it stabilizes and afterwards another jump is witnessed. The behavior exhibits a step-like stability. From the year 1986 up to 1992, a progressive marginal increase in exchange rate was witnessed, but in the year 1992 a jump was noticed and the exchange rate stabilized at that level up to the year 1999 where a sharp rise was witnessed. For a decade after that, a 
progressive gradual increase was witnessed though there were periods where mild fall in exchange rate was witnessed. Following the global financial crises, in the year 2009, another sharp jump was witnessed after which stability was noticed up to the year 2015 where another jump occurred which lasted a year. The year 2016 witnessed another jump in exchange rate stabilizing at a ridge up to the present.

From the graphical illustration, there seemed to be co-movement between oil price and exchange rate from 1986 up to the year 2000 after which oil price continued to rise gradually but exchange rate jumped and then settled in. In the year preceding the global financial crises (year 2007), oil price reached its zenith, but exchange rate declined a bit. Following the crises, oil price dipped but a sharp jump in exchange rate was noticed and even when oil price recovered and rose to the high level and stabilized, exchange rate did not respond, it remained at its level. When from the year 2014 oil price began to fall, exchange rate on the other hand began to depreciate, exhibiting an inverse relationship between the variables even though in the past a positive behavior between the variables was exhibited.

\subsection{Data and Methodology}

Following the approach of Enders and Siklos (2001); Aliyu and Tijjani (2015), we employed the Threshold Autoregressive (TAR) and Momentum Autoregressive (MTAR) models to examine whether or not the relationship between oil price and exchange rate in Nigeria is non-linear. Findings from these econometric tools aided us in deciding whether there were asymmetries in the relationship between oil price and exchange rate or not. The TAR and MTAR models are extensions of the Engle and Granger (1987) Two Steps to Cointegration Technique. While Engle and Granger (1987) is a symmetric test for cointegration, the TAR and MTAR models developed by Enders and Siklos (2001) are asymmetric technique for testing the presence of cointegating relationship among variables. Going by the arguments of Engle and Granger (1987), the regression of a non-stationary series on another non-stationary series breeds spurious regression, but however if the linear combination of the two series produces a stationary process, then the relationship between the variables is no longer spurious and the variables can be 
termed as being cointegrated (Abubakar, 2016b).

To determine whether our variables are stationary, we employed both linear and non-linear unit root test. For the linear unit root test, the Augmented Dickey Fuller (ADF) test for unit root was employed, the test shows the order of integration of variables $(I(d))$ i.e. the number of times $(d)$ a series have to be differenced before it becomes stationary. Considering the fact that we are interested in asymmetries, we employed the Kapetanios, et al. [KSS] (2003) non-linear unit root test. Under the assumption of no intercept and trend ${ }^{2}$, the ADF test for unit root is specified as:

$$
\Delta y_{t}=\beta y_{t-1} \sum_{i=1}^{j} \varphi \Delta y_{t-i}+\mu_{t}
$$

Under this test, the null hypothesis of $\beta=0$ is tested against the alternative hypothesis that $\beta<0$. If the null hypothesis is rejected, we conclude that the series is stationary i.e. it contains no unit root.

On the other hand, the KSS non-linear unit root test has the specification of:

$$
\Delta y_{t}=\sum_{i=1}^{j} \varphi \Delta y_{t-i}+\psi y_{t-1}\left\{1-\exp \left(-\theta y_{t-1}^{2}\right)\right\}+\mu_{t}
$$

Equation two can be implemented by an auxiliary regression specification which includes a cubic term of the form:

$$
\Delta y_{t}=\delta_{t-1}^{3}+\sum_{i=1}^{j} \varphi \Delta y_{t-i}+\mu_{t}
$$

From equation 2, the null hypothesis that $\theta=0$ is tested against the alternative of $\theta>0$, this is implemented by obtaining the t statistic of $\delta$ in equation 3. Rejection of the null hypothesis leads to the conclusion that the series is a non-linear Exponential Smooth Transition Autoregressive (ESTAR) process, i.e. globally stationary (Kapetanios, Shin and Shell, 2003).

If all variables are found to be non-stationary, we proceeded with testing for the presence of cointegration between the variables. To begin the Engle and Granger

\footnotetext{
${ }^{2}$ Note however that both intercept and trend can be added to the estimation of the $\mathrm{ADF}$ test. We make this assumption here just for the sake of simplistic specification.
} 
(1987) approach, we run a simple linear regression between Exchange Rate $\left(Y_{t}\right)$ and Oil Price $\left(X_{t}\right)$ using the specification:

$$
Y_{t}=C_{0}+\gamma X_{t}+e_{t}
$$

where: $C_{0}$ - Intercept Term; $\gamma$ - slope coefficient and $e_{t}$ - residual term.

After estimating equation 4, we obtain the linear relationship between the variables by making $\mu_{t}$ (i.e. the estimated $e_{t}$ ) subject of formula. This is because the residuals are the linear combination of the variables.

$$
\mu_{t}=Y_{t}-\gamma X_{t}
$$

To determine whether cointegration exists between the variables, we subject the residual term $\mu_{t}$ to $\mathrm{ADF}$ unit root test. If the residuals are found to be stationary, we conclude that cointegration exists between the variables, but if the residuals are non-stationary, there exist no cointegrating relationship between the variables. The ADF unit root test in the form of equation 6 was employed to test for cointegration.

$$
\Delta \mu_{t}=\rho \mu_{t-1} \delta_{t-1}^{3}+\sum_{i=1}^{j} \beta \Delta \mu_{t-i}+\varepsilon_{t}
$$

where: $\Delta$ is the difference operator and $\varepsilon_{t}$ is iid.

From the ADF test specified in equation 6, the null hypothesis of no-cointegration is specified as: $\rho=0$. If the null hypothesis is rejected, we will conclude that the variables are cointegrated.

The Two Step approach to cointegration is employed if the adjustment pattern of the relationship between study variables is symmetric, but if the adjustment exhibits an asymmetric behavior, the Two Step approach becomes invalid. To cater for this, Enders and Siklos (2001) introduced a cointegration test to be adopted in the event the adjustment behavior exhibits an asymmetric behavior. This methodology is termed as the TAR and MTAR models and it is an extension to the Two Step approach to cointegration based on Tong (1990). The approach of Enders and Siklos (2001) begins by splitting the first lag sequence of the residual 
$\left(\mu_{t-1}\right)$ in equation (6) into two partitions: one for deviations above the threshold and the other for deviations below the threshold value. The threshold value $(\tau)$ is derived endogenously, following the approach of Chan (1993) where in the bottom and top 10 per cent or 15 per cent values of the first lagged sequence of the residual $\left(\mu_{t-1}\right)$ are excluded depending on whether the samples are large or small respectively and each of the remaining values are treated as potential threshold in the calculation of the TAR or MTAR model, the threshold value of the model with the lowest Residual Sum of Squares (RSS) is regarded as the threshold value (Aliyu and Tijjani, 2015). To partition the first lagged sequence of the residual $\left(\mu_{t-1}\right)$ in equation 6 into two, we introduce a Heaviside indication function $\left(I_{t}\right)$ which takes the form of a dummy variable. For TAR model, the $\left(I_{t}\right)$ is specified as:

$$
I_{t}= \begin{cases}1, & \text { if } \mu_{t-1} \geq r \\ 0, & \text { if } \mu_{t-1}<r\end{cases}
$$

In equation $6, I_{t}$ takes the value of 1 if the value of the lagged sequence of the residual is above the threshold value and 0 if otherwise. By so doing, the lagged sequence of the residual becomes partitioned into above and below the threshold value hence taking an asymmetric dimension.

Following the specification of equation 7, we extend equation 6 to test for asymmetric cointegration between the variables. Substituting the specifications of equation 7 into equation 6 , the adjustment process of the TAR model is specified as

$$
\Delta \mu_{t}=I_{t} \rho_{1} \mu_{t-1}+\left(1-I_{t}\right) \rho_{2} \mu_{t-1}+\sum_{i=1}^{j} \beta_{i} \Delta \mu_{t-1}+\varepsilon_{t}
$$

In equation 8 , the terms $\rho_{1} \mu_{t-1}$ and $\rho_{2} \mu_{t-1}$ accounts for adjustments above and below the threshold value $(\tau)$, and the speed of adjustments is measured by the coefficients $\rho_{1}$ and $\rho_{2}$ respectively. But if the adjustment is found to be persistent in one direction more than the other i.e. for example it is more persistent towards deviation above threshold, Enders and Siklos (2001) offered an alternative specification where in instead of the speed of adjustment to be based on first lagged sequence of the residual $\left(\mu_{t-1}\right)$, it will now be based on the change in the lagged sequence of the residual i.e. $\left(\Delta \mu_{t-1}\right)$. This new specification is referred to as the Momentum Threshold Autoregressive (MTAR) model. The Heaviside indication 
function $\left(I_{t}\right)$ of the MTAR model is specified as:

$$
I_{t}= \begin{cases}1, & \text { if } \Delta_{t-1} \geq r \\ 0, & \text { if } \Delta_{t-1}<r\end{cases}
$$

To determine whether the deviations are more persistent in one direction, we compare the absolute values of the speed of adjustment $(\rho)$. If $\left|\rho_{1}\right|$ is very much different from $\left|\rho_{2}\right|$, we can conclude that the deviations are more persistent in one direction, hence the need to employ the MTAR model. It must be noted that the coefficients of adjustment $\left(\rho^{\prime} s\right)$ just like in the ADF test must be $-2<\left(\rho_{1}, \rho_{2}\right)<0$, otherwise there is no adjustment.

To test for the presence of asymmetric cointegration in both the TAR and MTAR model, we test the null hypothesis of no-cointegration specified as: $\rho_{1}=\rho_{2}=0$ against the alternative hypothesis that at least either $\rho_{1}$ or $\rho_{2}$ is not zero. If the null hypothesis is rejected, we can thus conclude that asymmetric cointegration exist between the variables. The test follows an F-distribution with critical value found in Enders and Siklos (2001). The next step in the analysis is to determine whether or not the adjustment process of the errors is symmetric or asymmetric. To do this, we test the null hypothesis of symmetric adjustment given by: $\rho_{1}=\rho_{2}$ against the alternative hypothesis of asymmetric adjustment given by $\rho_{1} \neq \rho_{2}$. If the null hypothesis of symmetric adjustment is rejected, we conclude that the adjustment process is asymmetric and the relationship between the variables is non-linear. Under the TAR and MTAR model, we can have four specifications of the model, the TAR, TAR Consistent, MTAR and MTAR Consistent. What differentiates the TAR and MTAR from TAR Consistent and MTAR Consistent is that while in the former we assumed a threshold value of 0 , in the latter and allowed for endogenous determination of the threshold value using the Chan (1993) approach.

If cointegration as well as asymmetric adjustment process is confirmed, the next step in the analysis is to estimate the Asymmetric Error Correction Model (AECM). But if evidence of asymmetric adjustment cannot be found from the TAR and MTAR model, the AECM model cannot be applied, but however linear econometric models such as Vector Autoregressive Model, Structural Vector Autoregressive 
Model (VAR), Vector Error Correction Model (VECM), Autoregressive and Distributed Lag Model (ARDL), Error Correction Model (ECM) etc. can be employed for further analysis. Unlike in the conventional ECM where there is only one error correction term; in the AECM two error correction terms are incorporated into the model, one capturing speed of adjustment to long run equilibrium for deviations above equilibrium and the other capturing speed of adjustment to long run equilibrium for deviations below the equilibrium. The conventional ECM is specified as:

$$
\Delta Y_{t}=\alpha_{0}+\theta \mu_{t-1}+\sum_{i=1}^{p} \delta_{i} \Delta Y_{t-i}+\sum_{i=1}^{p} \pi_{i} \Delta X_{t-i}+v_{t}
$$

where: $\alpha$ - Intercept; $\theta$ - Speed of adjustment to long run equilibrium; $V_{t}$ - error component.

By extending the conventional ECM in equation 10 and incorporating two error correction terms, the AECM is thus specified as:

$$
\Delta Y_{t}=\alpha_{0}+\theta_{1} A_{t}+\theta_{2} \forall_{t}+\sum_{i=1}^{p} \delta_{i} \Delta Y_{t-i}+\sum_{i=1}^{p} \pi_{i} \Delta X_{t-i}+v_{t}
$$

In equation $11, A_{t}=I_{t} \cdot \mu_{t-1}$ and $\forall_{t}=\left(1-I_{t}\right) \mu_{t-1}$ representing deviations above and below the long run equilibrium respectively. $\theta_{1}$ and $\theta_{2}$ measures the speed of adjustment towards long run equilibrium for deviations above and below equilibrium respectively. For exogeneity assumption of $X_{t}$ to be satisfied, both $\theta_{1}$ and $\theta_{2}$ have to be statistically significant, but if otherwise we say that $X_{t}$ is weakly exogenous suggesting that it does not respond to equilibrium errors (Aliyu and Tijjani, 2015). To examine the presence or otherwise of short run causality, we test the hypothesis $\pi_{i}=0$; if the hypothesis is rejected we conclude that there is presence of short run causality running from $X_{t}$ to $Y_{t}$.

In our study, evidence of asymmetric cointegration was not found, so for further analysis, we employed the Structural Vector Autoregressive (SVAR) model to examine impact of oil price shocks on exchange rate in Nigeria. We included foreign reserve $(\mathrm{FR})$ in the model because it matters for understanding the relationship between oil price and exchange rate. Instead of Sim (1980) VAR model, the SVAR 
model was employed because under the SVAR, to retrieve structural shocks, economic theory and empirics are used to identify the model. This is unlike in the Sim's VAR where the identification follows a recursive scheme (Abubakar, 2016b). The equation $^{3}$ of the SVAR model is specified as:

$$
A e_{t}=B \varepsilon_{t}
$$

Where $A$ is a matrix of contemporaneous relationship between the endogenous variables and $\mathrm{B}$ is a variance co-variance matrix.

To identify our model, we employ the zero (exclusion) restrictions ${ }^{4}$ on the elements of the $A$ matrix. Restricting an element of the A matrix to zero indicates absence of contemporaneous correlation. Unlike studies that employ the recursive identification where the $A$ matrix is made a lower triangular such that successive variables affects the preceding without feedback effect from the preceding to the succeeding variable, we employ economic intuition to impose restrictions on $A$ matrix. Consequently, our $A$ matrix is identified as:

$$
A=\left(\begin{array}{ccc}
1 & a_{12} & a_{13} \\
0 & 1 & 0 \\
0 & a_{32} & 1
\end{array}\right)
$$

The variance-covariance $(B)$ matrix is specified as:

$$
B=\left(\begin{array}{ccc}
b_{11} & 0 & 0 \\
0 & b_{22} & 0 \\
0 & 0 & b_{33}
\end{array}\right)
$$

Hence the equation in matrix form for retrieving the structural shocks from the reduced form errors is specified as:

$$
\left(\begin{array}{c}
E_{\text {exr }} \\
E_{\text {oilpr }} \\
E_{f r}
\end{array}\right)=\left(\begin{array}{ccc}
1 & a_{12} & a_{13} \\
0 & 1 & 0 \\
0 & a_{32} & 1
\end{array}\right)\left(\begin{array}{c}
e_{\text {exr }} \\
e_{\text {oilpr }} \\
e_{f r}
\end{array}\right)
$$

Explaining on our identifying restrictions, in the first row of equation 15, we assumed that shocks to oil price and foreign reserves have bearing on exchange rate,

\footnotetext{
${ }^{3}$ For explanation of the derivation of the SVAR equation from the reduced for VAR specification, see Abubakar (2016b).

${ }^{4}$ Note that it is required that at least $\left(n^{2}-n\right) / 2$ restrictions be placed for the model to be just identified. $\mathrm{N}$ is the number of variables in the model.
} 
as a result, no zero restriction is place. However, in the second row of the equation, it is assumed that both exchange rate and foreign reserves have no effect on oil price, therefore $a_{21}$ and $a_{23}$ are restricted to zero. This is a plausible argument because oil prices are exogenously determined by the international oil market. In addition, we assume that oil price has impact on foreign reserves, this is because an increase in oil price is associated with higher foreign exchange earnings, contributing to higher foreign reserves. In addition, it was assumed in the third row that exchange rate has no effect on foreign reserves, therefore, $a_{31}$ is restricted to 0.

To examine the impact of oil price shocks on exchange rate in Nigeria, the impulse response function (IRF) from the estimated SVAR model was employed. The IRF shows the response of a variable (into time horizon) to a unit standard deviation shocks to itself and other variables in the model (Abubakar, 2016a; Abubakar, 2018). Monthly Time series on crude oil price (oilpr), Naira official exchange rate (exr), real effective exchange rate (reer) and foreign reserves (fr) were sourced from the Central Bank of Nigeria (CBN) Statistical database for the period January 1986 to June 2018. However, the data for real effective exchange rate is available from January 2008. All data were converted to their logarithmic form before employed analysis.

\subsection{Findings and Discussion}

\subsection{Stationarity Test}

This study employs both ADF unit root test and KSS non-linear unit root test. Findings of both tests are presented in Tables 1 and 2, respectively.

Table 1: ADF Unit Root Test Result

\begin{tabular}{cccccc}
\hline & \multicolumn{2}{c}{ Level } & \multicolumn{2}{c}{ First Difference } & \\
Variables & Intercept & $\begin{array}{c}\text { Intercept } \\
\text { \&Trend }\end{array}$ & Intercept & $\begin{array}{c}\text { Intercept } \\
\text { \& Trend }\end{array}$ & $\begin{array}{c}\text { Order of } \\
\text { Integration }\end{array}$ \\
\hline LFR & -1.81 & -2.9 & $-17.02 * *$ & $-17.01 * *$ & $\mathrm{I}(1)$ \\
LOILPR & -1.56 & -2.87 & $-16.02 * *$ & $-15.99^{* *}$ & $\mathrm{I}(1)$ \\
LEXR & 1.67 & -3.25 & $-19.39^{* *}$ & $-19.54 * *$ & $\mathrm{I}(1)$ \\
LREER & -1.93 & -1.8 & $-10.21^{* *}$ & $-10.21 * *$ & $\mathrm{I}(1)$ \\
\hline
\end{tabular}


where $^{*}$ and ${ }^{* *}$ indicates rejection of $H_{0}$ at $5 \%$ and $1 \%$, respectively; $H_{0}$ : Series contain unit root (non-stationary). Table 1 presents the result of ADF unit root test. From the result it can be inferred that all variables were not stationary at their level form; they only became stationary after taking their first difference. We could thus conclude that the variables are integrated of order one $(I(1))$. From the non-linear unit root test presented in Table 2, the null hypothesis of the series could not be rejected for all the series when the test statistic was compared against the critical values contained in the Appendix. The result of the non-linear unit root test mimics the findings of the ADF unit root test.

Table 2: KSS Non-Linear Unit Root Test Result

\begin{tabular}{ccc}
\hline Variables & Test Statistic & Inference \\
\hline LFR & 1.555 & Non stationary \\
LOILPR & 0.549 & Non stationary \\
LEXR & 1.557 & Non stationary \\
LREER & 0.06 & Non stationary \\
\hline
\end{tabular}

$H_{0}$ : Series contain unit root (non-stationary).

\subsection{Cointegration Test}

Having determined that our variables are non-stationary in their level form, we determine whether our variables are cointegrated or not. Going by our study objectives, we conduct both the Engle and Granger (1987) Two Step (symmetric) cointegration test and the Enders and Siklos (2001) TAR and MTAR (asymmetric) cointegration tests. Results of the tests are presented in Table 3.

In Table $3, \Psi_{f}$ represents the F-statistic for testing the asymmetric cointegration hypothesis of $\rho_{1}=\rho_{2}=0, \Omega_{f}$ represents the F-statistic for testing the asymmetric adjustment hypothesis of $\rho_{1}=\rho_{2}$, while $\tau$ represents the threshold value. The 
critical values of TAR and MTAR for $\Psi_{f}$ and $\Omega_{f}$ as well as the critical values for the TAR Consistent and MTAR Consistent were generated using Monte Carlo Simulation using Eviews9.

Table 3: Symmetric and Asymmetric Cointegration Test Results

\begin{tabular}{cccccc}
\hline & E\& G & TAR & MTAR & $\begin{array}{c}\text { TAR } \\
\text { Consistent }\end{array}$ & $\begin{array}{c}\text { MTAR } \\
\text { Consistent }\end{array}$ \\
\hline $\mathrm{P}$ & $-3.18^{* *}$ & - & - & - & - \\
& $(-1.94)$ & & & & \\
$\rho_{1}$ & - & -0.017 & -0.027 & -0.013 & -0.02 \\
$\rho_{2}$ & - & $-0.036^{*}$ & $-0.0264^{*}$ & $-0.046^{*}$ & $-0.052^{*}$ \\
& & & & 5.639 & 5.514 \\
$\Psi_{\mathrm{f}}$ & - & $(5.962$ & $4.403(6.534)$ & -7.197 & $(7.953)$ \\
& & & & 3.053 & 2.173 \\
$\Omega_{\mathrm{f}}$ & - & 1.094 & $0.0014(3.918)$ & -6.202 & $(8.643)$ \\
& & $(2.349)$ & & -0.95 & -0.124 \\
\hline & - & 0 & 0 & & \\
\hline
\end{tabular}

where ${ }^{*}$ and ${ }^{* *}$ represents statistical significance at $5 \%$ and $1 \%$, respectively and critical values are given in parenthesis. From the Engle and Granger (1987) symmetric cointegration result presented in Table 3, the ADF computed statistic of -3.18 was found to be greater than the critical value of -1.94 at one percent level of significance. Since the computed statistic is greater than the critical value, we reject the null hypothesis of no-cointegration and conclude that there exist a symmetric cointegration between crude oil price and exchange rate of the Naira. However, since the theory and empirical reviews highlight the possibility of non-linear relationship, the TAR and MTAR asymmetric cointegration tests were employed. Results of TAR, MTAR, TAR Consistent and MTAR Consistent cointegration test did not provide enough evidence for the presence of asymmetric cointegration between the exchange rate and crude oil price for Nigeria because the null hypotheses of no cointegration could not be rejected as the computed statistics ( $\Psi_{f}$ in Table 3) was found to be less than the critical values at five percent level of significance. The adjustment pattern was also examined by testing the hypothesis of $\rho_{1}=\rho_{2}$, results of this test as presented in Table 3 , did not provide evidence for asymmetric adjustment pattern of errors because the computed F-statistic $\left(\Omega_{f}\right)$ cutting across the whole stream of TAR and MTAR models estimated was found to be less than 
the critical values (in parenthesis) hence we cannot reject the null hypothesis of symmetric adjustment of errors. From the different cointegration tests presented in Table 3, it can be seen that there is no asymmetric cointegration between crude oil price and official exchange rate of the naira and the adjustment of errors (as seen from F-statistic $\left(\Omega_{f}\right)$ exhibits a symmetric and not an asymmetric behaviour, hence validating the result of the Engle and Granger (1987) cointegration results obtained. The finding of symmetric relationship between the variables conforms to the findings of Volkov and Yuhn (2016) and Babatunde (2015), among others; and contrary to findings such as Ahmad and Hernanadez (2013). It could, thus, be concluded that the pass through of changes in oil price to exchange rate of the naira is symmetric. Therefore, in estimating the relationship between the variables, the application of linear models is more appropriate.

\subsection{SVAR Model Result}

For a better analysis of the exchange rate and oil price relationship, the study estimated two models for examining the impact of oil price shocks on exchange rate. Two variants of exchange rates were utilized, they are the official exchange rate of the naira to the dollar and the real effective exchange rate. The estimated structural parameters are presented in the Appendix. However, the IRF plot in Figure 2 should be interpreted with caution because the underlying structural coefficients were found to be statistically insignificant.

Under this section, we present the impulse response function generated from the estimated SVAR models. The IRFs are presented in Figures 2 to 4 . Figure 2 presents the response of official exchange rate to a unit shocks in oil price into time horizon. From the IRF plot, for the first few period horizon exchange rate was found to show no response to oil price shocks but after the fourth period horizon, a progressive negative response was noticed. This negative response though increasing gradually continued until the end of the tenth period horizon. The implication of the finding is that exchange rate in Nigeria responds to oil price shocks sluggishly. At the initial state no response occurs, but with time the exchange rate begins to decrease marginally leading to gradual appreciation of the Naira. 


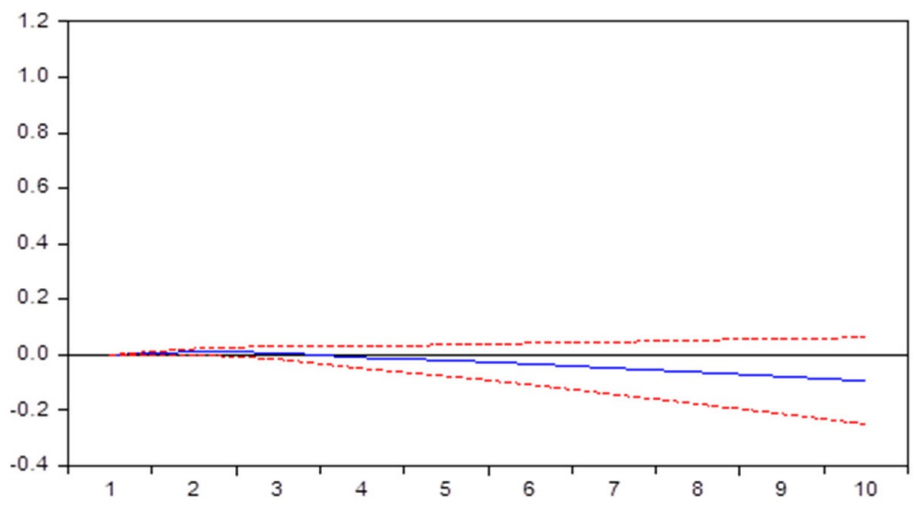

Figure 2: Response of Official Exchange Rate to Shock in Oil Price.

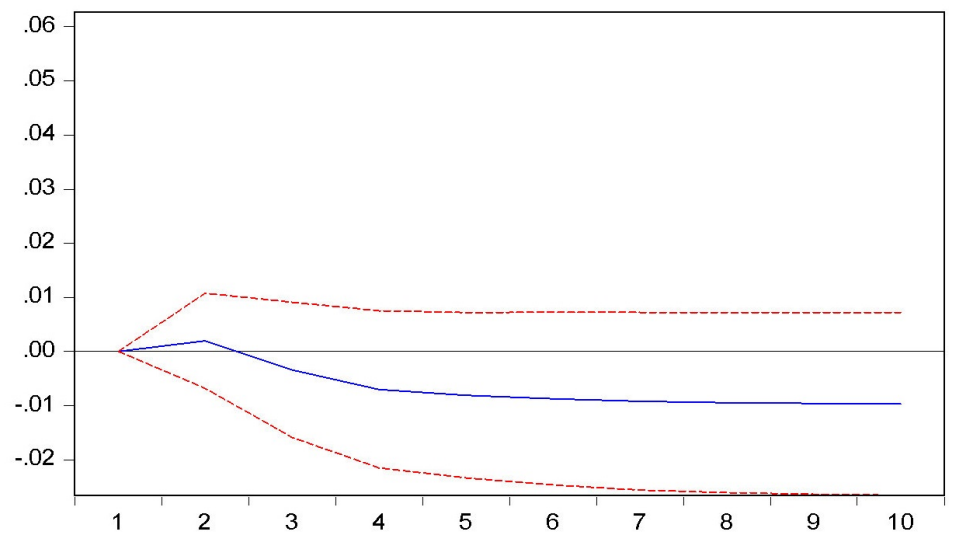

Figure 3: Response of Real Effective Exchange Rate to Shock in Oil Price

For robustness checks, another SVAR model was estimated, however the real effective exchange rate (REER) instead of the official exchange rate was employed for analysis. The IRF from this model indicates that following a positive shock in oil price, a very mild positive response of REER was noticed, however, from the second month up to the tenth month horizon, a progressive negative response of REER was noticed, though the rate of progression reduced with movement into time horizon. This finding indicates that positive oil price shock leads to the appreciation of the naira, although this happens after a short lag of months. This finding is somewhat mimic the results obtained from the official exchange rate model, the major difference is the lags taken before the appreciation of naira sets 
in which happens to be longer under the official exchange rate model. The finding of exchange rate appreciation following increase in oil prices is in tandem with findings of Lizardo and Mollick (2010); Mordi and Adebiyi (2010) and Abed et al. (2016), among others.

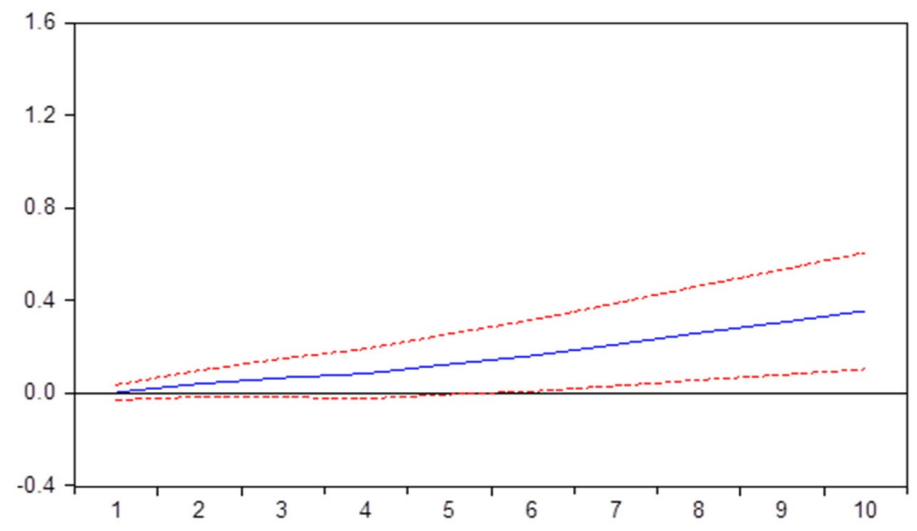

Figure 4: Response of Foreign Reserve to shock in Oil price.

Figure 4 presents the response of FR to a unit shock in oil price. From the IRF plot, it can be seen that from the first period horizon, FR exhibited a progressive positive response to shock in oil price with the response becoming more pronounced with more movement into time horizon, the response line continued to move further away from the equilibrium line. We could thus infer from the finding that in Nigeria, positive oil price shock has a positive bearing on the foreign reserves.

\subsection{Conclusion and Policy Recommendations}

The study sought to examine whether there are asymmetries in the relationship between oil price and exchange rate in Nigeria, and the nature of pass through of oil price shocks to the Naira exchange rate. Both linear and non-linear models were employed for the analysis. The study found no asymmetries in the relationship between exchange rate and oil price which leads to the conclusion that the relationship between the variables is linear and not non-linear. Further, exchange rate exhibited a gradual appreciating response to oil price shocks though with time lag. Foreign Reserve was also found to respond positively to oil price shocks. 
Based on the study results, we recommend that policy makers take cognizance of oil price in making exchange rate policy decisions. Since oil price is exogenously determined, over dependence on oil as the major source of foreign exchange earnings must be curtailed to mitigate the negative effects. To ensure this, the export base of the economy must be diversified, by venturing into less volatile commodities and finished products. In addition, policies aimed at attracting foreign exchange inflow into the economy via foreign direct investment and foreign portfolio investment should also be considered. Finally, there is the need to alter the international trade base of the economy via policies geared towards import substitution, particularly of petroleum finished products and other products that we have the potentials to produce locally, so as to reduce pressure on forex market.

\section{References}

Abed, R.E., Amor, T.H., Nouira, R., \& Rault, C. (2016). Asymmetric effect and dynamic relationships between oil prices shocks and exchange rate volatility: evidence from some selected MENA countries. Topics in Middle Eastern and African Economies, 18 (2).

Abubakar, A.B. (2016a). Economic growth impact of Indian stock market: an econometric investigation. Pacific Business Review International (Finance section), 1(1).

Abubakar, A.B. (2016b). Dynamic effects of fiscal policy on output and unemployment in Nigeria: an econometric investigation. CBN Journal of Applied Statistics, 7(2).

Abubakar, A.B. (2017). Impact of oil sector on macroeconomic stability of the Nigerian economy. In proceeding of the International Conference on Defence, Security, Economy and Development in Nigeria, organized by Department of History and War Studies, Nigerian Defence Academy, Kaduna-Nigeria on 27th Febuary, 2017.

Abubakar, A.B. (2018). Does agricultural sector matter for the growth of an oil dependent economy? empirical evidence from Nigeria. Journal of Economic Policy and Research, 13(1): 119-131.

Adeniyi, O., Omisakin, O., Yaqub, J., \& Oyinlola, A. (2012). Oil price-exchange rate nexus in Nigeria: further evidence from an oil exporting economy. International Journal of Humanities and Social Sciences, 2(8). 
Ahmad, A. H., \& Hernandez, R. M. (2013). Asymmetric adjustment between oil prices and exchange rates: empirical evidence from major oil producers and consumers. Journal of Financial Markets, Institutions and Money, 27, 306-317.

Aliyu, J.A., \& Tijjani, S.M. (2015). Asymmetric cointegration between exchange rate and trade balance in Nigeria. Cogent Economics \& Finance, 3.

Amano, R. A., \& Van Norden, S. (1998). Exchange rates and oil prices. Review of International Economics, 6(4), 683-694.

Atems, B., Kapper, D., \& Lam, E. (2015). Do exchange rates respond asymmetrically to shocks in the crude oil market? Energy Economics, 49, 227-238.

Babatunde, M.A. (2015). Oil price shocks and exchange rate in Nigeria. International Journal of Energy Sector Management, 9(1), 2-19.

Beckmann. J., \& Czudaj, R. (2013). Oil prices and effective Dollar exchange rates. International Review of Economics, 27, 621-636.

Bénassy-Quéré, A., Mignon, V., \& Penot, A. (2007). China and the relationship between the oil price and the dollar. Energy Policy, 35, 5795-5805.

Blanchard, O., \& Perotti, R. (2002). An Empirical Characterization of the Dynamic Effects of Changes in Government Spending and Taxes on Output. The Quarterly Journal of Economics, 117 (4), 1329-1368.

Brahmasrene, T., Huang, j., \& Sissoko, Y. (2014). Crude oil price and exchange rates: causality, variance decomposition and impulse response function. Energy Economics, 44, 407-412.

Brayek, A.B., Sebai, S., \& Naoui, K. (2015). A study of the interactive relationship between oil price and exchange rate: a coupla approach and a DCCMGARCH model. The Journal of Economic Asymmetries, 12(2), 173-189.

Buetzer, S., Habib, M.M., \& Stracca, L. (2012). Global exchange rate configurations: do oil shocks matter? European Central Bank Working Paper No. 1442 .

Central Bank of Nigeria. (2017). Statistical Bulletin.

Chan, K. S. (1993). Consistency and limiting distribution of the least squares estimator of a threshold autoregressive model. The Annals of Statistics, 21, $520-533$.

Chen, H., Wang, Y., \& Zhu, Y. (2016). Oil price shocks and the US Dollar exchange rates. Energy, 112, 1036-1048. 
Dickey, D.A., \& Fuller, W.A. (1979). Distribution of the estimators for autoregressive time Series with a unit root. Journal of the American Statistical Association, 74(1), 427-431.

Enders, W., \& Siklos, P. L. (2001). Cointegration and threshold adjustment. Journal of Business \& Economic Statistics, 19, 166-176.

Energy Information Administration. (2018). Energy Statistics. Retrieved from https://www.eia.gov/

Engle, R.F., \& Granger, W.J. (1987). Cointegration and error correction: representation, estimation and testing. Econometrica, 55, 251-276.

Fowowe, B. (2014). Modeling the oil price-exchange rate nexus for South Africa. International Economics, 140, 36-48.

Fratzscher, M., Schneider, D., \& Robay, I.V. (2014). Oil prices, exchange rates and assets prices. European Central Bank Working Paper No 1689.

Golub, S. (1983). Oil prices and exchange rates. The Economic Journal, 93, 576-593.

Hussain, M., Zebende, G.F., Bashir, U., \& Donghong, D. (2017). Oil price and exchange rate co-movements in Asian countries: detrended cross-correlation approach. Physica: A Statistical Mechanics and its Applications, 465, 338346.

Kapetanios, G., Snell, A. \& Shin, Y. (2003). Testing for a unit root in the nonlinear STAR framework. Journal of Econometrics, 112, 359-379.

Krugman, P. (1983). Oil and the Dollar, NBER Working Papers 0554.

Lizardo, R.A., \& Mollick, A.V. (2010). Oil price fluctuations and US Dollar exchange rates. Energy Economics, 32(2), 399-408.

Muhammad, Z., Suleiman, H., Kouhy, R. (2011). Exploring oil price and exchange rate nexus for Nigeria. FIW Working Paper No 71.

Mordi, C. N.O. \& Adebiyi, M.A. (2010). The Asymmetric effects of oil price shocks on output and prices in Nigeria using a Structural VAR model. $C B N$ Economic and Financial Review, 48(1).

National Bureau of Statistics. (2017). Nigerian Gross Domestic Product Report Quarter 3, 2017.

Ogundipe, A., \& Ogundipe, O. (2013). Oil price and exchange rate volatility in Nigeria. MPRA Paper 51668. 
Ogundipe, O.M., Ojeaga, P., \& Ogundipe, A.A. (2014). Oil price and exchange rate volatility in Nigeria. IOSR Journal of Economics and Finance, 5(4), $1-9$.

Pershin, V., Molero, J.C., \& Perez De Gracia, F. (2016). Exploring the oil prices and exchange rates nexus in some African economies. Journal of Policy Modeling, 38(1), 166-180.

Reboredo, J.C. (2002). Modelling oil price and exchange rate co-movements. Journal of Policy Modelling, 34(3), 419-440.

Sims, C. (1980). Macroeconomics and reality. Econometrica, 48 (1), 1-48.

Syed, A.B., Alfred, A.H., \& Perry, S. (2012). Oil Prices, exchange rates and emerging stock markets. Energy Economics, 34(1), 227-240.

Tiwari, A.k., Mutascu, M.L., \& Albulescu, C.T. (2013). The influence of the international oil prices on the real effective exchange rate in Romania in a wavelet transform network. Energy Economics, 40, 714-733.

Tiwari, K.A., \& Albulescu, T.C. (2016). Oil price fluctuations and exchange rate in India: fresh evidence from continuous wavelet approach and asymmetric multi-horizon granger causality test. Applied Energy, 179, 272-283.

Tong, H. (1990). Non-linear time series: A dynamical system approach. Oxford: Oxford University Press.

Turhan, M.I., Sensoy, A., \& Hacihansanoglu, E. (2014). A comparative analysis of the dynamic relationship between prices and exchange rates. Journal of International Financial Institutions and Money, 32, 397-414.

Uddin, G.S., Tiwari, A.K., Arouri, M., \& Teulon, F. (2003). On the relationship between oil price and exchange rates: a wavelet analysis. Economic Modeling, 35, 502-507.

Volkov, N.I., \& Yuhn, K. (2016). Oil prices shocks and exchange rate comovements. Global Financial Journal, 31, 18-30.

Wang, Y., \& Wu, C. (2012). Energy prices and exchange rates of the US Dollar: further evidence from linear and non-linear causality analysis. Economic Modeling, 29(6), 2289-2297. 


\section{Appendices}

Parameter Estimates of the SVAR Official Exchange Rate Model

\begin{tabular}{|l|l|l|}
\hline & Coefficient & Standard Errors \\
\hline $\mathrm{C}(1)$ & -0.013377 & 0.015847 \\
$\mathrm{C}(2)$ & 0.000269 & 0.013830 \\
$\mathrm{C}(3)$ & -0.019452 & 0.058399 \\
$\mathrm{C}(4)$ & $0.101400^{*}$ & 0.003654 \\
$\mathrm{C}(5)$ & $0.326103^{*}$ & 0.011752 \\
$\mathrm{C}(6)$ & $0.088492^{*}$ & 0.003189 \\
\hline \multicolumn{3}{|c|}{ A Matrix } \\
\hline 1 & $\mathrm{C}(1) \quad \mathrm{C}(3)$ \\
0 & 1 & 0 \\
0 & $\mathrm{C}(2)$ & 1 \\
\hline \multicolumn{3}{c}{$\mathrm{B}$ Matrix } \\
\hline $\mathrm{C}(4)$ & 0 & 0 \\
0 & $\mathrm{C}(5)$ & 0 \\
0 & 0 & $\mathrm{C}(6)$ \\
\hline
\end{tabular}

* Indicates statistical significance at 5\% significance level.

Parameter Estimates of the SVAR Real Effective Exchange Rate Model

\begin{tabular}{|l|l|l|}
\hline & Coefficient & Standard Errors \\
\hline $\mathrm{C}(1)$ & $-0.120016^{*}$ & 0.047293 \\
$\mathrm{C}(2)$ & -0.012612 & 0.032879 \\
$\mathrm{C}(3)$ & 0.169255 & 0.128331 \\
$\mathrm{C}(4)$ & $0.046115^{*}$ & 0.002940 \\
$\mathrm{C}(5)$ & $0.088905^{*}$ & 0.005674 \\
$\mathrm{C}(6)$ & $0.032399^{*}$ & 0.002066 \\
\hline \multicolumn{3}{|c|}{ A Matrix } \\
\hline 1 & $\mathrm{C}(1)$ & $\mathrm{C}(3)$ \\
0 & 1 & 0 \\
0 & $\mathrm{C}(2)$ & 1 \\
\hline \multicolumn{3}{|c}{$\mathrm{B}$ Matrix } \\
\hline $\mathrm{C}(4)$ & 0 & 0 \\
0 & $\mathrm{C}(5)$ & 0 \\
0 & 0 & $\mathrm{C}(6)$ \\
\hline
\end{tabular}

* Indicates statistical significance at 5\% significance level. 
KSS (2003) Non-linear Unit Root Test Asymptotic Critical Values

\begin{tabular}{|c|c|}
\hline Significance Level & Statistic \\
\hline $1 \%$ & -2.89 \\
$5 \%$ & -2.22 \\
$10 \%$ & -1.92
\end{tabular}

Note: The critical values are in the case of raw data 